\title{
Competencia educativa
}

\author{
Education competence
}

\author{
Virginia Argüelles-Pascual ${ }^{a}$, David Hernández-Palacios ${ }^{b}$, Iris B. Cuevas-Rivera $^{c}$, Efraín \\ Andrade-Hernández ${ }^{d}$
}

\begin{abstract}
:
In this work, a driagram is presented that represents the education competence and the elements that compose it. In the first instance, the types of education competence identified in the literature studied are shown, as well as the level of competence developed. The scheme ilustrates the intervention of the teacher and the student. Likewise, a representation of the evaluation by competencies is made, a definition is made, as well as a definition and the way in which it is evaluated, the types and techniques of evaluation, the degree of performance and the evaluation matrix are exposed.
\end{abstract}

Keywords:

Education competence, Competences assessment, teacher, student

Resumen:

En este trabajo se expone un diagrama que representa la competencia educativa y los elementos que la componen. En primera instancia, se muestran los tipos de competencia educativa identificadas en la literatura estudiada, así como el nivel de competencia que desarrolla. El esquema ilustra la intervención del profesor y del estudiante. De igual forma, se hace una representación de la evaluación por competencias, así como una definición y se expone la manera en cómo se evalúa, los tipos y técnicas de evaluación, el grado de desempeño y la matriz de valoración.

\section{Palabras Clave:}

Competencia educativa, evaluación por competencias, profesor, estudiante

\section{Introducción}

La competencia educativa es la capacidad de respondera diferentes situaciones e implica un saber hacer que se refiere a las habilidades con saberque se refiere a los conocimientos, así como la valoración de las consecuencias de ese hacer que son los valores y actitudes. Existen tres tipos de competencias educativas: básicas, genéricas y específicas. Las competencias básicas se enfocan a las competencias cognitivas, técnicas y metodológicas. Las competencias genéricas hablan del perfil del egresado y en particular se refiere a los conocimientos, habilidades, actitudes y valores. Las competencias específicas que trata el comportamiento, específicamente de los conceptos, teorías, conocimientos instrumentales y habilidades de investigación. La competencia educativa se evalúa a través de los juicios sobre los aprendizajes logrados, las evidencias y la retroalimentación de los alumnos. En dicho proceso intervienen tanto el profesor y el estudiante. El primero se conduce como organizador, colaborativo, creativo e innovador, planificador, responsable y aplicador de pilares de la educación. En cuanto al estudiante debe conocerse y valorarse así mismo, propone solución a problemas, aprende por iniciativa propia, participa y colabora, y tiene conciencia propia ${ }^{1,2}$.

En este trabajo (Figura 1) se presenta un diagrama con los elementos esenciales de la competencia educativa.

\footnotetext{
a Autor de Correspondencia, Universidad Autónoma del Estado de Hidalgo, Email: apascual@ uaeh.edu.mx

${ }^{\text {b }}$ Centro Universitario Vasco de Quiroga de Huejutla, Email: david.h.palacios.cuvaqh@ gmail.com

c Universidad Autónoma del Estado de Hidalgo, Email: icuevas@uaeh.edu.mx

dUniversidad Autónoma del Estado de Hidalgo, Email: efrain_andrade8310@uaeh.edu.mx
} 


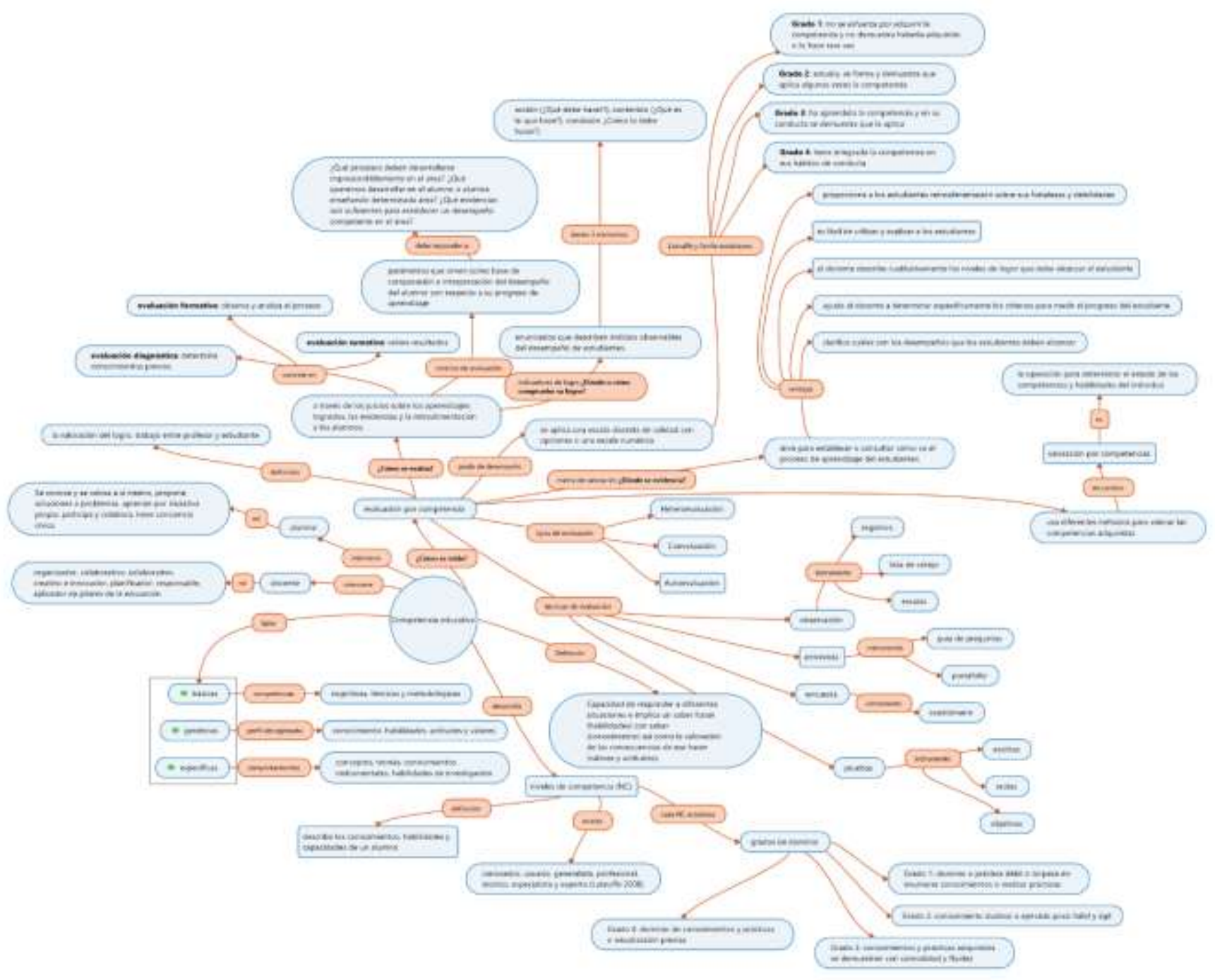

Figura 1. Elementos que explican la competencia educativa.

\section{Referencias}

[1] Labruffe, Alain (2008). La gestión de competencias: planteamientos básicos, prácticas y cuadros de mando. Madrid: AENOR..

[2] Senlle, Andrés (2007). Gestión estratégica de recursos humanos para la calidad y la excelencia. Madrid: AENOR.. 